НАУКОВИЙ ВІСНИК

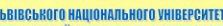
РИнаРНӦ̈ МЕДИИИНИ ТА БОТЕКНОЛО імені С.3. гжищьког Scientific messenger of L Lviv National Univer
Veterinary Medicine and Biotechnologie

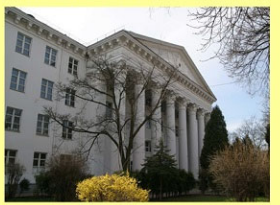

СЕРІЯ “ЕКОНОМІчн НАУКИ"

Том 21 № 93

2019

Науковий вісник Дьвівського національного університету ветеринарної медицини та біотехнологій імені С.3. Гжицького. Серія: Економічні науки

\author{
Scientific Messenger of Lviv National University \\ of Veterinary Medicine and Biotechnologies. \\ Series: Economical Sciences
}

UDC 303.832

\title{
Verification of final ranking which received because of the expert evaluation
}

\author{
O.I. Stepanyuk, V.P. Novosad
}

Stepan Gzhytskyi national university of veterinary medicine and biotechnologies Lviv, Ukraine

Article info

Received 20.09.2019

Received in revised form 22.10 .2019

Accepted 25.10.2019

Stepan Gzhytskyi National University of Veterinary Medicine and Biotechnologies Lviv,

Pekarska Str., 50, Lviv, 79010, Ukraine.

Tel.: +38-093-515-46-46

E-mail:k_itm@ukr.net
Stepanyuk, O.I., \& Novosad, V.P. (2019). Verification of final ranking which received because of the expert evaluation. Scientific Messenger of Lviv National University of Veterinary Medicine and Biotechnologies. Series: Economical Sciences, 21(92), 96-101. doi: 10.32718/nvlvet-e9319

In the modern dynamic information society, situations that are characterized by complexity, multifactoriality, uncertainty, and non-formalization occur very often. Under such conditions, the adoption of effective management decisions is impossible without interaction with the expert environment. This applies to a wide range of human activities, including economic issues. The article is devoted to one of the key stages of expert evaluation - the analysis of members of expert commissions' judgments and drawing up final conclusions. The author aims to get closer to solving one of the key problems characteristic to this stage, namely: truth verification problems, reliability confirmation for final conclusions obtained as a result of generalization of expert groups' work. Most often, the experts are asked to compare certain objects according to certain criteria, to identify the best and the worst among them. It is clear that expert judgments are rarely unanimous. Therefore, it is important to apply scientific approaches to constructing final ranking, that is, the final location of objects in order of increase or decrease of a certain quality or usability. The mathematical modeling of activity of an expert group conducted by the author of the article made it possible to identify cases where, depending on the applied techniques, the final rankings obtained on the basis of the judgments of the same experts may differ (sometimes even substantially). This again emphasizes the need to verify the final rankings. The advantages and disadvantages of applying quantitative and qualitative methods in expert-analytical activity are also considered. The scientific novelty of the conducted research is to improve the methodological approaches that will allow to improve the consistency of expert judgments, and to develop recommendations for the complex application of separate methods for constructing total ranking. The article is intended for scientists and practitioners who are interested in contemporary sociological and management approaches to solving economic problems. Also, the article may be useful for specialists and programmers who work in the field of development of artificial intelligence.

Key words: expert-analytical activity, expert evaluation, final ranking of objects, verification of expert judgments, modeling of expert activity, coefficient of concordance.

\section{Верифікація підсумкових ранжувань, отриманих внаслідок експертного оцінювання}

\author{
О.І. Степанюк, В.П. Новосад
}

Львівський національний університет ветеринарної медицини та біотехнологій імені С.3. Гжсицького, м. Львів, Україна

У сучасному динамічному інформачійному суспільстві дуже часто виникають ситуації, які характеризуються складністю, багатофакторністю, невизначеністю, неформалізованістю. За таких умов ухвалення ефективних управлінських рішень $\epsilon$ неможливим без взаємодї з експертним середовищем. Це стосується найрізноманітніших сфер людської діяльності, у тому числі й економічних питань. Стаття присвячена одній з ключових стадій експертного очінювання - аналізу суджень членів експертних комісій. виробленню остаточних висновків. Автор ставить за мету наблизитись до розв'язання однієї з ключових проблем, притаманних цій стадії, а саме: проблеми перевірки істинності, підтвердження достовірності тих остаточних висновків, які отримуються в результаті узагальнення роботи експертних груп. Найчастіше перед експертами ставиться завдання порівняти 
за визначеними критеріями певні об’єкти, виявити найкращі та найгірші серед них. Зрозуміло, щяо експертні судження нечасто виявляються одностайними. Тому важливо застосувати наукові підходи до побудови підсумкових ранжувань, тобто заключного розташування об'єктів в порядку зростання чи спадання певної якості чи придатності до застосування. Проведене автором статті математичне моделювання діяльності експертної групи дозволило виявити випадки, коли в залежності від застосованих методик підсумкові ранжування, отримані на основі суджень одних і тих же експертів, можуть відрізнятись (часом навіть суттєво). Це ще раз підкреслює необхідність верифікації підсумкових ранжувань. Також розглядаються переваги та недоліки застосування кількісних і якісних методів в експертно-аналітичній діяльності. Наукова новизна проведених досліджень полягає у вдосконаленні методологічних підходів, які дозволять покращчити узгодженість експертних суджень, і виробленні рекомендацій стосовно комплексного застосування окремих методів побудови підсумкових ранжувань. Стаття призначена для науковців та практиків, яких цікавлять сучасні соціологічні та управлінські підходи до вирішення економічних проблем. Також стаття може бути корисною для фахівців та програмістів, які працюють у сфері розроблення штучного інтелекту.

Ключові слова: експертно-аналітична діяльність, експертні оцінки, підсумкові ранжування об'єктів, верифікація експертних суджень, моделювання експертної діяльності, коефіцієнт конкордації.

\section{Вступ}

У сучасному динамічному інформаційному суспільстві неможливо ухвалювати ефективні управлінські рішення без урахування думки фахівцівпрофесіоналів. Усвідомлення цього призвело до необхідності забезпечення наукового супроводу процесів взаємодії з експертним середовищем. Тому вчені та практики всього світу все більше увагу приділяють розвитку та реалізації відносно нового наукового напрямку (сформувався після другої світової війни) - теорії експертного оцінювання (Litvak, 2004). Зауважимо, що йдеться не про технологічні експертизи, коли об'єкти оцінюють за суто формалізованими показниками, які піддаються чіткому вимірюванню. Мова йде про ситуації, які можна визначити як багатофакторні, складні, невизначені, неформалізовані тощо.

Експерти повсякчас залучаються до вирішення найрізноманітніших завдань у багатьох сферах людської діяльності. Кожний 3 класичних етапів експертного оцінювання (Novosad et al., 2009) є посвоєму важливим та потребує науково-обгрунтованих підходів. Однак, на думку авторів статті, найбільш вагомої методологічної та інформаційно-аналітичної підтримки заслуговують такі стадії експертного оцінювання:

1) підготовка первинної інформації для експертів;

2) підбір членів експертної комісії;

3) аналіз суджень експертів.

Кожну 3 цих стадій можна назвати критичною. Адже неякісна реалізація будь-якої з них 3 високою вірогідністю призведе до необ'єктивних заключних висновків.

У рамках цієї публікації автори ставлять за мету продовжити дослідження, які тісно пов'язані 3 проблемою верифікації результатів, тобто перевірки їхньої істинності, підтвердження достовірності тих остаточних висновків, які отримуються внаслідок аналізу індивідуальних для кожного експерта ранжувань певних об'єктів за визначеними критеріями.

Наведені у статті міркування та рекомендації можна застосувати для аналізу експертних суджень в економіці та управлінні. Зокрема, у сучасній науковій та академічній літературі подібні питання розглядались під час оцінювання персоналу (Mizintseva \& Sardaryan, 2019), туристичного потенціалу регіонів (Novosad, 2019), мотиваційного середовища туристичних підприємств (Vy’nogradova et al., 2015).

Аналіз цих та інших публікацій, співдотичних до теми статті, дозволяє зробити важливі узагальнення та поставити пов'язані 3 ними завдання, які тезисно можна подати таким чином.

1. Експерти можуть виражати свою думку кількісно або якісно.

Кількісний підхід може полягати, наприклад, в оцінюванні кожного об'єкта за визначеними заздалегідь критеріями, бальною шкалою та ваговими коефіцієнтами. Кількісні дані відносно легко опрацьовувати методами прикладної статистики. Водночас, під сумнів підпадає коректність виставлених балів. Адже дуже важко для складних неформалізованих об'єктів точно сказати, у скільки разів чи на скільки один 3 них кращий від іншого.

Якісний підхід більш природний. Експерт, підключивши досвід, здоровий глузд та інтуїцію, робить порівняння за допомогою слів “кращий”, “гірший”, “дуже поганий”, “поганий”, “задовільний”, “хороший”, “дуже хороший”, “відмінний”. Проте повноцінне оброблення таких даних наштовхується на проблеми кількісно-якісного та якісно-кількісного трансформування і вимагає застосування спеціальних методів статистики об'єктів нечислової природи.

Важко сподіватись, що в науковій літературі чи офіційних довідниках будуть опубліковані статистичні дані щодо використання кількісних та якісних методів експертного оцінювання в практичній діяльності. Цінність цих методів в конкретних випадках можна було б перевірити шляхом розробки та застосування таких комплексних методик, коли рівною мірою використовується кожен підхід.

2. На практиці найчастішим завданням, яке ставиться перед експертними групами, є порівняння певних об'єктів, виявлення найкращих та найгірших серед них. Зрозуміло, що в такому разі головним результатом роботи експертів має бути підсумкове ранжування, під яким розуміють розташування об'єктів в порядку зростання (спадання) їхньої якості (значущості, важливості, ефективності, прибутковості, собівартості ...).

3. Підсумкове ранжування має якимось чином враховувати думку всіх (або майже усіх у випадку відкидання суджень дисидентів) членів експертної комісії. Підсумкове ранжування можна будувати як на основі індивідуальних ранжувань (отриманих кожним 
експертом зокрема), так і на основі спеціальних процедур (розрахунків), що дозволяють узагальнити судження експертів.

4. Зважаючи на складність об'єктів експертизи (а саме тоді вона є потрібною), неважко припустити, що судження експертів мають дещо відрізнятись. Тому разом 3 побудовою підсумкових ранжувань важливо провести спеціальні дослідження стосовно узгодженості суджень членів експертної комісії. Щоб охарактеризувати це найчастіше використовують коефіцієнти конкордації Кендала (Kendel, 1975) (для встановлення загального рівня узгодженості) та коефіцієнти рангової кореляції Спірмена (Novosad, 2009) (для встановлення узгодженості суджень для пар експертів). Існують також методики, які дозволяють за допомогою цих коефіцієнтів виявити групові точки зору. Часто такі дані дозволяють відразу дати вичерпні рекомендації щодо побудови підсумкових ранжувань. Наприклад, загальновідомо, що у випадку хорошої узгодженості підсумкове ранжування можна отримати шляхом застосування методу середніх арифметичних до індивідуальних ранжувань.

\section{Матеріал і методи досліджень}

Здійснимо математичне моделювання роботи експертної комісії, яка складається 35 осіб (Е1, E2, E3, E4, E5) і оцінює 6 об'єктів (А, В, C, D, E, F) за 4 характеристиками (a, b, c, d). Вважаємо, що вагові коефіцієнти характеристик були встановлені на основі результатів попередніх аналогічних експертиз із застосуванням спеціальних методів (один з таких методів розглянуто, наприклад, у статті [8]). Нехай ці коефіцієнти мають значення $q_{1}=\frac{3}{8} ; q_{2}=\frac{1}{4} ; q_{3}=\frac{1}{4} ; q_{4}=\frac{1}{8}$. По іншому це можна сформулювати так: перший критерій у 3 рази важливіший, ніж четвертий, а другий і третій у 2 рази важливіші, ніж четвертий. Для наочності розглянемо конкретний випадок, коли оцінювання відбувається за п'ятибальною шкалою і приводить до результатів, відображених на рис. 1.

\begin{tabular}{|c|c|c|c|c|c|c|c|c|c|c|c|c|c|}
\hline \multicolumn{7}{|c|}{ E1 } & \multicolumn{7}{|c|}{ E2 } \\
\hline \multirow{2}{*}{$\begin{array}{l}\text { кри- } \\
\text { терії }\end{array}$} & \multicolumn{6}{|c|}{ Об'єкти } & кри- & \multicolumn{6}{|c|}{ Об'єкти } \\
\hline & A & B & C & $\mathrm{D}$ & $\mathrm{E}$ & $\mathrm{F}$ & терії & A & B & C & $\mathrm{D}$ & $E$ & $\mathrm{~F}$ \\
\hline$a$ & 5 & 4 & 5 & 4 & 4 & 3 & $a$ & 5 & 5 & 4 & 4 & 4 & 4 \\
\hline $\mathrm{b}$ & 4 & 4 & 4 & 4 & 4 & 4 & b & 5 & 4 & 5 & 4 & 5 & 5 \\
\hline c & 5 & 4 & 5 & 4 & 5 & 4 & c & 5 & 5 & 5 & 5 & 4 & 4 \\
\hline d & 4 & 4 & 3 & 3 & 4 & 5 & d & 2 & 3 & 3 & 4 & 5 & 4 \\
\hline \multicolumn{7}{|c|}{ E3 } & \multicolumn{7}{|c|}{ E4 } \\
\hline кри- & \multicolumn{6}{|c|}{ Об'єкти } & кри- & \multicolumn{6}{|c|}{ Об'єкти } \\
\hline терії & A & B & $C$ & D & $\mathrm{E}$ & $\mathrm{F}$ & терії & A & B & $C$ & D & $E$ & $\mathrm{~F}$ \\
\hline a & 4 & 3 & 4 & 5 & 4 & 3 & $a$ & 5 & 3 & 4 & 4 & 4 & 3 \\
\hline b & 4 & 4 & 5 & 4 & 4 & 4 & b & 4 & 5 & 5 & 5 & 4 & 4 \\
\hline C & 5 & 4 & 3 & 3 & 3 & 4 & c & 4 & 4 & 5 & 4 & 5 & 5 \\
\hline d & 3 & 4 & 4 & 3 & 4 & 5 & d & 3 & 5 & 3 & 3 & 3 & 5 \\
\hline \multicolumn{7}{|c|}{ E5 } & & & & & & & \\
\hline кри- & \multicolumn{6}{|c|}{ Об'єкти } & & & & & & & \\
\hline терії & A & B & C & $\mathrm{D}$ & $E$ & $\mathrm{~F}$ & & & & & & & \\
\hline a & 4 & 4 & 5 & 4 & 4 & 3 & & & & & & & \\
\hline$b$ & 5 & 2 & 4 & 4 & 3 & 5 & & & & & & & \\
\hline c & 5 & 5 & 4 & 4 & 3 & 4 & & & & & & & \\
\hline d & 3 & 4 & 5 & 3 & 4 & 4 & & & & & & & \\
\hline
\end{tabular}

Рис. 1. Первинні результати експертного оцінювання

Продемонструємо для розглядуваного випадку різні методики побудови підсумкових ранжувань.

Відповідно до методу еталонних бальних оцінок (Novosad et al., 2009) остаточні оцінки кожного 3 шести об'єктів знаходимо за формулами

$$
x_{i}=\sum_{j=1}^{5} \sum_{k=1}^{4} q_{k} x_{i j k},(i=1,2,3,4,5,6),
$$

де $x_{i j k}$ - оцінка $i$-го об'єкта $j$-им експертом за $k$-ою характеристикою, $q_{k}$ - вагові коефіцієнти характеристик. Результати обчислень і встановлені на основі цього рейтинги наведено у табл. 1.

\section{Таблиця 1}

Рейтинги об'єктів за критерієм еталонних бальних оцінок

\begin{tabular}{lcccccc}
\hline & $\mathrm{A}$ & $\mathrm{B}$ & $\mathrm{C}$ & $\mathrm{D}$ & $\mathrm{E}$ & $\mathrm{F}$ \\
\hline Бальні оцінки & 22 & 19,875 & 21,75 & 20,125 & 20 & 19,625 \\
Рейтинг & 1 & 5 & 2 & 3 & 4 & $6(1)$ \\
\hline
\end{tabular}

Наступні два пропоновані методи вимагають попереднього встановлення індивідуальних для кожного експерта рейтингів на основі зважених оцінок об'єктів. Зважені оцінки наведено у табл. 2.

Спираючись на ці оцінки, встановлюємо відповідні нормовані рейтинги, які відображає табл. 3. 
Таблиця 2

Зважені оцінки об’єктів для кожного експерта

\begin{tabular}{ccccccc}
\hline & $\mathrm{A}$ & $\mathrm{B}$ & $\mathrm{C}$ & $\mathrm{D}$ & $\mathrm{E}$ & $\mathrm{F}$ \\
\hline E1 & 4,625 & 4 & 4,5 & 3,875 & 4,25 & 3,75 \\
E2 & 4,625 & 4,5 & 4,375 & 4,25 & 4,375 & 4,25 \\
E3 & 4,125 & 3,625 & 4 & 4 & 3,75 & 3,75 \\
E4 & 4,25 & 4 & 4,375 & 4,125 & 4,125 & 4 \\
E5 & 4,375 & 3,75 & 4,5 & 3,875 & 3,5 & 3,875 \\
\hline
\end{tabular}

Таблиця 3

Індивідуальні для кожного експерта рейтинги об’єктів

\begin{tabular}{ccccccc}
\hline & A & B & C & D & E & F \\
\hline E1 & 1 & 4 & 2 & 5 & 3 & 6 \\
E2 & 1 & 2 & 3,5 & 5,5 & 3,5 & 5,5 \\
E3 & 1 & 6 & 2,5 & 2,5 & 4,5 & 4,5 \\
E4 & 2 & 5,5 & 1 & 3,5 & 3,5 & 5,5 \\
E5 & 2 & 5 & 1 & 3,5 & 6 & 3,5 \\
\hline
\end{tabular}

Підсумкові рейтинги об'єктів, тобто такі, які відображають судження усієї експертної групи в цілому, встановлюємо як за методом середніх арифметичних, так i за методом медіан індивідуальних рейтингів. Результати також подаємо у табличній формі (табл. 4 і табл. 5).

\section{Таблиця 4}

Підсумкові рейтинги об'єктів за критерієм середніх арифметичних індивідуальних рейтингів

\begin{tabular}{lcccccc}
\cline { 2 - 6 } & $\mathrm{A}$ & $\mathrm{B}$ & $\mathrm{C}$ & $\mathrm{D}$ & $\mathrm{E}$ & $\mathrm{F}$ \\
\hline Середнє арифметичне індивідуальних рейтингів & 1,4 & 4,5 & 2 & 4 & 4,1 & 5 \\
Підсумковий рейтинг & 1 & 5 & 2 & 3 & 4 & 6 \\
\hline
\end{tabular}

\section{Таблиця 5}

Підсумкові рейтинги об’єктів за критерієм медіан індивідуальних рейтингів

\begin{tabular}{lcccccc}
\cline { 2 - 6 } & $\mathrm{A}$ & $\mathrm{B}$ & $\mathrm{C}$ & $\mathrm{D}$ & $\mathrm{E}$ & $\mathrm{F}$ \\
\hline Медіанне значення індивідуальних рейтингів & 1 & 5 & 2 & 3,5 & 3,5 & 5,5 \\
Підсумковий рейтинг & 1 & 5 & 2 & 3,5 & 3,5 & 6 \\
\hline
\end{tabular}

Зауважимо, що результати табл. 4 отримані 3 припущенням, що судження кожного експерта $\epsilon$ однаково важливі або, іншими словами, експерти мають рівну компетентність.

Іншим напрямком верифікації отриманих результатів $є$ дослідження загального рівня узгодженості суджень між експертами. Для цього використовувався коефіцієнт конкордації, який обчислюється за формулою:

$$
W=\frac{12 \sum_{j=1}^{m} \Delta_{j}^{2}}{n^{2}\left(m^{3}-m\right)}
$$

де $\Delta_{i}$ - сума квадратів відхилень суми рангів кожної характеристики від загальної середньої суми рангів, $n$ - кількість експертів, $m$ - кількість об'єктів.

При цьому нами пропонується методика, яка вимагає обчислення всієї можливої сукупності коефіцієнтів конкордації: для усіх 5 експертів, для усіх можливих комбінацій з 4, 3 та 2 експертів. Це дає можливість зробити висновки не тільки про загальну узгодженість суджень, але й про:

a) дисидента, тобто експерта, судження якого найбільш кардинально відрізняються від решти;

b) експерта 3 "центральною думкою", тобто такого, судження якого мінімально відрізняються від загальної думки (підсумкового ранжування);

c) групові точки зору.

Розрахований за формулою (2) коефіцієнт конкордації для усієї експертної групи становить , що в принципі говорить про доволі $W=0,60$ прийнятний рівень. У табл. 7 наведено інші коефіцієнти для усіх можливих конфігурацій експертів. Індекси показують для яких саме експертів обчислено коефіцієнт конкордації.

Зауважимо також цікаву, на наш погляд, тенденцію, яка полягає в тому, що зі зростанням кількості експертів, для яких коефіцієнт конкордації обчислюється, середнє його значення спадає. 


\section{Таблиця 7}

Коефіцієнти конкордації для різних конфігурацій експертів

\begin{tabular}{|c|c|c|c|}
\hline & Для чотирьох експертів & Для трьох експертів & Для двох експертів \\
\hline & $W_{1234}=0,65$ & $W_{345}=0,79$ & $W_{12}=0,87$ \\
\hline & $W_{1235}=0,573$ & $W_{245}=0,54$ & $W_{13}=0,76$ \\
\hline & $W_{1245}=0,61$ & $W_{235}=0,53$ & $W_{14}=0,87$ \\
\hline & $W_{1345}=0,72$ & $W_{234}=0,57$ & $W_{15}=0,69$ \\
\hline & $W_{2345}=0,566$ & $W_{145}=0,73$ & $W_{23}=0,54$ \\
\hline & & $W_{135}=0,69$ & $W_{24}=0,60$ \\
\hline & & $W_{134}=0,78$ & $W_{25}=0,52$ \\
\hline & & $W_{125}=0,60$ & $W_{34}=0,85$ \\
\hline & & $W_{124}=0,72$ & $W_{35}=0,84$ \\
\hline & & $W_{123}=0,64$ & $W_{45}=0,80$ \\
\hline Середнє & 0,62 & 0,66 & 0,73 \\
\hline
\end{tabular}

\section{Результати та їх обговорення}

Побудуємо підсумкові ранжування, використавши для цього рейтинги об'єктів, наведені в останніх рядках табл. $1,4,5$. Порівняльний аналіз здійснюємо за допомогою табл. 6.

\section{Таблиця 6}

Підсумкові ранжування, отримані різними методами

\begin{tabular}{lc}
\hline \multicolumn{1}{c}{ Метод } & $\begin{array}{l}\text { Підсумкове } \\
\text { ранжування }\end{array}$ \\
\hline Еталонних бальних оцінок & $\mathrm{A}<\mathrm{C}<\mathrm{D}<\mathrm{E}<\mathrm{B}<\mathrm{F}$ \\
Середнє арифметичне індивідуальних & $\mathrm{A}<\mathrm{C}<\mathrm{D}<\mathrm{E}<\mathrm{B}<\mathrm{F}$ \\
рейтингів & $\mathrm{A}<\mathrm{C}<\mathrm{D}=\mathrm{E}<\mathrm{B}<\mathrm{F}$ \\
Медіана індивідуальних рейтингів
\end{tabular}

Відзначимо, що позначенням $\mathrm{x}<\mathrm{y} \quad \mathrm{B} \quad$ теорії експертного оцінювання прийнято підтверджувати той факт, що об'єкт х “кращий” від об'єкта у, а позначення $\mathrm{x}=\mathrm{y}$ позначає рівність властивостей.

Таким чином, отримані підсумкові ранжування практично ідентичні, що можна трактувати як один 3 аргументів на користь підтвердження якості експертизи і довіри до ії результатів.

Числові дані, наведені в табл. 7, дозволяють зробити низку додаткових проміжних висновків про узгодженість експертизи:

1. Експертом з “центральною думкою” є Е1, оскільки ігнорування його суджень приводить до максимального зниження коефіцієнта конкордації.

2. Дисидентом $\epsilon$ E2, оскільки ігнорування його суджень приводить до максимального підвищення коефіцієнта конкордації.

3. Існують неявно виражені групи $\{\mathrm{E} 1, \mathrm{E} 2\}$ та $\{\mathrm{E} 3$, $\mathrm{E} 4, \mathrm{E} 5\}$ з подібними поглядами.

4. Якщо не враховувати судження дисидента (як це роблять, наприклад, у деяких видах спорту, відкидаючи крайні точки зору), то під час наступного етапу дослідження узгодженості суджень вже між експертами Е1, E3, E4, E5 дисидентом виявиться E1, тобто той, хто за умови врахування судження дисидента Е2 був експертом
3 “центральною думкою”. Цей висновок, на наш погляд, є цікавим з управлінської точки зору.

У випадку невеликої кількості експертів інколи доцільно відображати узгодженість їхніх суджень графічно. Результати, отримані у статті, проілюстровані на рис. 2 многогранником, відстань між вершинами якого характеризує близькість суджень між відповідними експертами (чим менша відстань, тим ближче судження), а площа трикутників пропорційна узгодженості суджень трійок експертів.

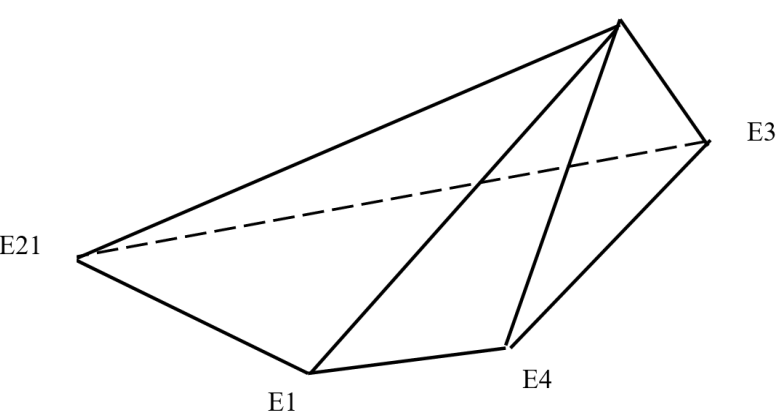

Рис. 2. Многогранник близькості суджень експертів

Зрозуміло, що в загальному випадку, коли число експертів більше чотирьох, такі графічні унаочнення $\epsilon$ не зовсім коректними з математичної точки зору, оскільки наштовхуються на проблеми відображення n-вимірного простору. Проте їх можна застосовувати для наочності зроблених вище висновків.

У цілому, проведені додаткові дослідження щодо узгодженості думок членів експертної комісії $є$ ще одним аргументом на користь об’єктивності іiі остаточних результатів.

Важливо розуміти, що якість експертизи (достовірність, істинність, об'єктивність) великою мірою залежать від відповідальної, доброчесної та науково-обгрунтованої взаємодії всіх зацікавлених ланок. Порушення цих умов може призвести до суттєвої нестійкості результатів. Наприклад, якщо в розглянутому нами випадку припустити, що всі характеристики об'єктів є рівноважливими (як це 
часто неявно мається на увазі у розроблених для потреб економіки та управління методиках), то підсумкове ранжування суттєво зміниться і набуде вигляду: $\mathrm{C}<\mathrm{A}<\mathrm{F}<\mathrm{E}<\mathrm{B}<\mathrm{D}$. Як бачимо об'єкти А та $\mathrm{F}$, які за умови врахування ваги характеристик займали протилежні полюси (перше і останнє місце), тепер стали сусідами (друге і третє місце).

\section{Висновки}

Проведене авторами статті математичне моделювання (застосовано три різних методи для побудови підсумкових ранжувань і модифікований метод коефіцієнтів конкордації для перевірки узгодженості суджень експертів) накреслює один 3 можливих підходів для підтвердження якості проведеної експертизи.

Разом 3 тим можливі випадки, коли в залежності від застосованих методик підсумкові ранжування, отримані на основі суджень одних і тих же експертів, можуть відрізнятись (часом навіть суттєво), що ще раз підкреслює необхідність верифікації.

Стійкість результатів залежить не тільки від застосованих методів, але й від якості первинної інформації, яка досягається шляхом науково обгрунтованої взаємодії з експертними групами.

Перспективи подальших досліджень. Об'єктивна реальність не має залежати від методу, що використовується для іiі вивчення. Тому постають питання:

1. Якими є межі застосовності методів побудови підсумкових ранжувань?

2. Який метод заслуговує на більшу довіру?

3. Як згладити протиріччя, отримані в результаті застосування різних методів?

4. Коли остаточному результату можна довіряти?

У подальших дослідженнях автори планують зосередити свої зусилля на вирішенні двох останніх запитань i сподівається впровадити отримані результати у соціально-економічну сферу та надати рекомендації щодо створення відповідних інформаційних систем підтримки управлінських рішень.

\section{References}

Kendel, M. (1975). Rangovyie korrelyatsii. M.: Statistyika (in Russian).

Litvak, B.G. (2004). Ekspertnyie tehnologii v upravlenii. M.: Delo (in Russian).

Mizintseva, M.F., \& Sardaryan, A.R. (2019). Otsenka personala: uchebnik i praktikum dlya akademicheskogo bakalavriata. Moskva: Izdatelstvo Yurayt: https://urait.ru/bcode/432770 (in Russian).

Novosad, V.P. (2009). Otsiniuvannia uzghodzhenosti ekspertnykh vysnovkiv metodamy ranhovoi koreliatsii. Demokratychne vriaduvannia v konteksti hlobalnykh vyklykiv ta kryzovykh sytuatsii: materialy nauk.-prakt. konf. za mizhnar. uchastiu (3 kvit.2009 r., m. Lviv): u 2 ch. za nauk. red. chl.-kor. NAN Ukrainy V.S. Zahorskoho, dots. A.V.Lipentseva. Lviv: LRIDU NADU, 353-356 (in Ukrainian).

Novosad, V.P. (2019). Perspekty`vy` zastosuvannya texnologij ekspertnogo ocinyuvannya u tury`sty`chnij sferi. Zbirny'k tez naukovo-prakty'chnoyi konferenciyi "Sil's'ki tery'toriyi Ukrayiny”: stan ta perspekty`vy` rozvy`tku”, 16-17 travnya 2019 r. L'viv: LNUVMB imeni S.Z. Gzhy`cz'kogo, FOP Korpan B.I., 29-30 (in Ukrainian).

Novosad, V.P., Kukhar, R.B., \& Yeleiko, O.I. (2012). Optymizatsiinyi metod vyznachennia vahovykh koefitsiientiv bahatokryterialnoho ekspertno-ho otsiniuvannia. Upravlinnia sotsialno-ekonomichnymy protsesa-my zasobamy matematychnoho modeliuvannia ta informatsiinykh tekhnolohii: materialy naukovo-metodychnoho seminaru kafedry matematychnoho modeliuvannia ta informatsiinykh tekhnolohii. Lviv: LRIDU NADU, 69-71 (in Ukrainian).

Novosad, V.P., Seliverstov, R.G., \& Arty`m, I.I. (2009). Kil 'kisni metody' ekspertnogo ocinyuvannya: nauk.metod.rozrobka. K.: NADU (in Ukrainian).

Vy`nogradova, O.V., Gusyeva, O.Yu., \& Piligry`m, K.I. (2015). Naukovi problemy' doslidzhennya zovnishn`ogo moty`va-cijnogo seredovy`shha tury`sty`chny`x pidpry`yemstv. Mexanizmy` regulyuvannya ekonomiky`, 4, 38-45 (in Ukrainian). 